Full length article

\title{
A novel approach for enhancing green supply chain management using converged interval-valued triangular fuzzy numbers-grey relation analysis
}

\author{
Ming-Lang Tseng a ${ }^{a}$ Ming Lim ${ }^{\mathrm{b}}$, Kuo-Jui $\mathrm{Wu}^{\mathrm{c}, *}$, Li Zhou $^{\mathrm{d}}$, David Tat Dat Bui ${ }^{\mathrm{e}}$ \\ a Department of Business Administration (Scopus H-index: 20), Lunghwa University of Science and Technology, Taiwan \\ b Supply Chain Center, College of Management, University of Derby, UK \\ ' School of Business, Dalian University of Technology, Panjin, China \\ d Business School, The University of Greenwich, UK \\ e Department of Business Administration, Lunghwa University of Science and Technology, Taiwan
}

Keywords:

Converged interval-valued triangular fuzzy

numbers-grey relation analysis

Green supply chain management

\begin{abstract}
A B S T R A C T
The existing literatures are lacking on the cost and benefit concerns, screening the measures and convergence of interval-valued triangular fuzzy numbers-grey relation analysis (IVTFN-GRA) weight together. Nonetheless, Green supply chain management is always suffering the linguistic preferences and system incomplete information in evaluation process to enhance the performance. Yet, those previous studies are merely based on un-converged weight results. Hence, this study proposed a hybrid method to dealing with this multi-criteria evaluation problem. Fuzzy Delphi method proposes to screen the evaluation criteria and converged IVTFN-GRA weight method handles the vagueness system uncertainty and incomplete information with interdependence relations. Hence, the proposed hybrid method enhanced the green supply chain management and compared multi-methods to enhance their performance in Taiwanese electronic focal firm. The result showed that the converged weight is consistent with the real practices, despite the differences with the current average weighting method. The finding in the long-term perspective: resilience and operational improvement are the top weighted aspects.
\end{abstract}

\section{Introduction}

Green supply chain management (GSCM) is well-practiced by manufacturing firms in Taiwan as well as their supply chain networks. Now, manufacturers have reduced the harm to the natural environment when generating waste, disrupting the ecosystem and depleting natural resources. However, firms are still reluctant, or not effective, when implementing aspects of GSCM practices in the operations (Zhu et al., 2008; Wu et al., 2015). In a recent study, Olugu and Wong (2012) proposed that a suitable expert fuzzy rulebased, evaluation system is crucial for achieving a successful closed-loop supply chain in the automotive industry. Tseng and Chiu (2013) proposed using fuzzy- grey relation analysis (GRA) in choosing the suitable supplier as a key strategy in eliminat-ing environmental impact when using GSCM to improve a firm's

\footnotetext{
* Corresponding author.

E-mail addresses: tsengminglang@gmail.com (M.-L. Tseng), M.Lim@derby.ac.uk (M. Lim), wukuojui@dlut.edu.cn (K.-J. Wu), li.zhou@gre.ac.uk (L. Zhou), btdat1991@gmail.com (D.T.D. Bui).
}

performance. Tseng et al. (2014a,b) proposed the application of cost and benefit concerns on hybrid multi-criteria decision making (MCDM) to assist in the process of analyzing and selecting the alternatives aligned with the proposed criteria on both the qualitative and quantitative scales. However, as prior studies have shown, the consideration of MCDM results in the development of the GSCM in the decision-making process. Still, the main concern is that the literature neglects to include the cost and benefit concerns, screening the measures and convergence weight in the decision-making process. Moreover, the literature has not explained how to screen and validate the evaluation criteria and converged weights.

GSCM refers to a variety of methods and practices that firms can use enhance and retain performance within their products or processes. It has been considered as an approach to simultaneously deal with environment and economic concerns between suppliers and customers (Wu et al., 2015). Several studies investigated the relationship between GSCM and performance in order to explore the critical drivers for developing sustainability. For instance, Zhu et al. (2008) proposed environmental management, green purchasing, eco-design, environmental cooperation with customers 
and investment recovery to establish a model to evaluate performance. To confirm the performance of these practices, Jabbour et al. (2015) set 13 measures under environmental and operational performance to identify its potential relationships with GSCM. Furthermore, Malviya and Kant (2016) adopted strategic, organization, social-culture, buyer-supplier, legislation and technical enablers to measure the implementation of GSCM. Luthra et al. (2015) utilized critical success factors to develop GSCM structure in developing sustainability. GSCM studies continuously explore and validate measures for use in evaluating the performance of GSCM practices. Appropriate measurements aid in determining the critical drivers of GSCM, and these measurements can practically reflect the real situation of Taiwanese electronic manufacturing firms. To support the gap in measuring performance, MCDM enables to structure a logical and systematical model in reducing the complexity for enhancing the performance.

The MCDM method is a widely used approach for evaluating typical multiple-related criteria. In practice, qualitative and quanti-tative measures are used for determining the criteria performance, with respect to the criteria, and the relative importance of the evaluation criteria. Tseng and Chiu (2013) proposed choosing the suitable supplier as a key strategy in eliminating environmen-tal impact on GSCM using a fuzzy-grey relation analysis system to improve the firm's performance. Tadic et al. (2014) proposed selecting the best alternative using a complex hybrid decision making method, which consists of conflicting and uncertain ele-ments when solving the logistics problems. Rabbani et al. (2014) applied a branch of the MCDM technique and a sustainability bal-ance scorecard to evaluate the performance of firms that helped authorities toward achieving a competitive advantage. However, there are many related decisionmaking methodologies applied to the task of organizing and analyzing complex measures subject to uncertainties (Li et al., 2007; Wang and Chang, 2007; Tseng et al., 2014a,b). The main advantages of these methods are their inherent ability to handle intangibles and less cumbersome mathematical calculations. Prior studies have applied MCDM methods with fuzzy sets to address uncertainty and overcome the vagueness of exist-ing methods. Fuzzy sets and triangular fuzzy numbers (TFN) are often applied to express linguistic variables in studies (Cakir and Canbolat, 2008; Tseng and Chiu, 2013; Ren and Sovacool, 2014; Tseng et al., 2014a,b), whereas fuzzy set theory and MCDM have been useful in other researches (Ghorbani et al., 2013; Hague et al., 2015; Kahraman et al., 2010). However, decision-making process requires establishing interdependence relations among the measures, which has not been addressed in these recent studies. The IVTFN, GRA and converged weight methods are proposed to support interdependence relations and in consideration of the incomplete analytical information available.

Moreover, GRA has been successfully applied in diverse applications to address the incomplete system information. Wang et al. (2004) further applied the grey relation to the process evaluation in assigning rankings and scores to performances. Tseng (2009) used a solution based on a combined Grey-fuzzy making trial and eval-uation laboratory method to address service quality expectation ranking with uncertainty. In addition, Tseng (2009) presented a per-ception approach to address supplier evaluation of environmental knowledge management capacities with uncertainty and incom-plete information. Wang (2014) applied GRA and fuzzy techniques for order preference by similarity to ideal solutions to partition financial ratios into several clusters and to find representative indices from the clusters and then presented the evaluation criteria in a financial assessment of a Taiwan container shipping firm. The GRA is effective in evaluating and weighing the key criteria with limited information (Zhai et al., 2009; Tsai et al., 2012). However, prior studies rarely deliberated the cost and benefit concerns and converged weight method.
Therefore, the reason for applying TFN is ease of use in information processing and computational simplicity in linguis-tic preferences (Tseng, 2008; Wang et al., 2009). The values' range is relatively easy to determine. It is appropriate to define lower and upper bound values as interval value triangular fuzzy numbers (IVTFN) (Zhang and Liu, 2011). Still, the decision-making process needs to address the information incomplete in the analytical system. Hence, GRA aims to express the system information more precisely (Deng, 1989; Tseng, 2008). The study of Ashtiani et al. (2009) developed an interval-valued fuzzy weighting method to solve MCDM problems in which the rating values and the weights of criteria are linguistics terms, which can be expressed in IVTFN. Zhang et al. (2011) developed an extended GRA method for solving MCDM problems with unknown criterion weights. Wu et al. (2016) applied IVTFN associated with grey relational analysis to improve the insufficient information, cost and benefit concerns and overcome the incomplete system under uncertainties in sustainable supply chain management study. Nevertheless, the comparisons of multi-method with and without cost and benefit concerns involved in the analytical system are lacking. Still, the shortcoming of these previous studies is failed to involve converged weight method in the analytical result. Hence, the converged IVTFN-GRA is proposed.

To screen and validate the measures, the fuzzy Delphi method (FDM) has been proposed (Murray et al., 1985; Chang et al., 2011). Hence, the purpose of this study is to validate the measures and address the linguistic expressions, incomplete system information, cost and benefit concerns and converged weight method of the GSCM assessment. The objective of this study is to extract and analyze the GSCM attributes with the proposed FDM, compared multi-methods with or without cost and benefit concerns and lastly, the converged IVTFN-GRA to determine management priority. Such a proposed method can assist the firm in decisionmaking and in comparing similar methods that critically influence the decision-making of the firms' management. To demonstrate the effectiveness of the developed proposed method in facilitating the evaluation process, this study conducted on focal electronic manufacturing firms that implemented GSCM for past years.

The study's contribution is threefold: (1) using FDM to determine the GSCM measures; (2) verifying and comparing the usefulness of proposed IVTFN-GRA with and without cost and benefit concerns and weighted average method; and (3) acquiring the important GSCM attributes in the industrial practices. The rest of this paper is organized as follows: Section 2 describes FDM, the converged weight method of IVTFN-GRA and proposed approach; Section 3 presents a case study to demonstrate the feasibility and consistency of the extended proposed method; Section 4 applies to managerial implications in this study. Finally, the conclusions are discussed.

\section{Methods}

This section proposes a solutions method to address how the proposed traditional GRA, IVTFN-GRA with and without cost and benefit concerns method, performs the GSCM in the operations.

\subsection{Fuzzy delphi method}

Murray et al. (1985) proposed to integrate the Delphi method and fuzzy sets together involve at least two reviews by subjectmatter experts on the criteria. Kuo and Chen (2008) applied FDM to construct key appraisal indicators for mobility of the service industries. Hence, FDM screens the criteria in the first stage as this method can address the fuzziness of the common understanding of expert opinions and allow for evaluation on a more flexible scale. A fuzzy set, $\tilde{A}$, in a universe of discourse, $\mathrm{X}$, is characterized 
by the membership function, $\mu_{\AA}(\mathrm{x})$, that assigns each element, $\mathrm{x}$, in $\mathrm{X}$ a real number in the interval [0,1]. The numerical value $\mu_{A}$ ( $\mathrm{x}$ ) stands for the grade of membership of $\mathrm{x}$ in $\sim A$ (Triantaphyllou and Lin, 1996; Lu et al., 2007). Table 2 presents the corresponding interval-valued TFNs with linguistic preferences. A set of IVTFN $\tilde{a}$ is defined by a triangular $\tilde{a}=\left[\left(a_{1}, a_{1}^{\prime}\right) ; a_{2} ;\left(a_{3}^{\prime}, a_{3}\right)\right]$ with a membership function. The IVTFN is based on an interval-value judgment: the minimum possible value, $\left(a_{1}, a_{1}^{\prime}\right)$, the mean possible value, $a_{2}$, and the maximum possible value, $\left(a_{3}, a_{3}\right)$. The criteria values depend on linguistic pReferences

Assuming the value of the significance of $j$ elements given by $i$ experts is $\tilde{a}=\tilde{a}=\left[\left(a_{1}, a_{1}^{\prime}\right) ; a_{2} ;\left(a_{3}^{\prime}, a_{3}\right)\right]$, $i=1,2,3, \ldots . . n ; j=1,2,3, \ldots . m$. The weighting $\tilde{a}_{j}$ of $j$ elements is $\tilde{a}=\left[\left(a_{1}, a_{1}^{\prime}\right) ; a_{2} ;\left(a_{3}^{\prime}, a_{3}\right)\right]$, wherein $\left(a_{1}, a_{1}^{\prime}\right)_{j}=\min \left\{\left(a_{1}, a_{1}^{\prime}\right)_{i j}\right\}$, $a_{2 j}=\frac{1}{n} \sum_{1}^{n} a_{2 i j},\left(a_{3}^{\prime}, a_{3}\right)_{j}=\max \left\{\left(a_{3}^{\prime}, a_{3}\right)_{i j}\right\}$. Using the simple center of gravity method to reduce the fuzziness of the fuzzy weight, $\tilde{a}_{j}$, the definite value, $\tilde{R}_{j}$, is obtained. The proper criteria can be screened out from numerous criteria by setting the threshold, $\alpha$. The principles of screening are as follows: If $\tilde{R}_{j} \geq \alpha$, the $j$ criterion is accepted for the evaluation criterion; or If $\tilde{R}_{j}<\alpha$, then the criterion is unaccepted.

\subsection{Grey relationship analysis}

Suppose an MCDM problem has $x$ non-inferior criteria, $\mathrm{m} A_{1}, A_{2}$, $\cdots, A_{x}$, and $y$ aspects, $S_{1}, S_{2}, \cdots, S_{\mathrm{y}}$. The criteria are assessed with relation to $y$ aspects. The IVTFN are assigned to aspects and criteria with respect to a decision matrix denoted by $\tilde{D}=\left[\tilde{d}_{i j}\right]_{x \times y}$.

To normalize the decision matrix $d_{i j}$ (Zhang et al., 2011)

$\tilde{d}_{i j}=a_{i j} / \max \left(a_{i j}\right), i=1,2, \cdots, x ; j=1,2, \cdots, y$, forj $\in B$

$\tilde{d}_{i j}=\min \left(a_{i j}\right) / a_{i j}, i=1,2, \cdots, x ; j=1,2, \cdots, y$, forj $\in C$

Where $B$ presents the set of benefit criteria, and $C$ denotes the set of cost criteria, the range between two fuzzy numbers, $\tilde{C}=\left(C_{1}, C_{2}\right.$, $\left.C_{3}\right)$ and $\tilde{B}=\left(B_{1}, B_{2}, B_{3}\right)$, is computed as (Chang et al., 2011):

$\rho(\tilde{C}, \tilde{B})=\sqrt{\frac{1}{3}\left[\left(C_{1}-B_{1}\right)^{2}+\left(C_{2}-B_{2}\right)^{2}+\left(C_{3}-B_{3}\right)^{2}\right]}$

In order to determine the distance between the reference value and each comparison value, it is required to first obtain the reference series, $D_{0}=\left\{d_{01}, d_{02}, \cdots, d_{0 y}\right\}, d_{0 j}=\max _{j} d_{i j}, j=1,2, \cdots y$. The distances are denoted as $\rho_{i j}=d_{0 j}-d_{i j}$. The grey relational coefficient $\tau_{i j}$ is generated by $\tau_{i j}=\left(\rho_{\min }+\tau \rho_{\max }\right) /\left(\rho_{i j}+\tau \rho_{\max }\right), i=$ $1,2, \cdots, x ; j=1,2, \cdots, y$.

The $\rho_{\max }$ and $\rho_{\min }$ are the maximum and minimum of $\rho_{i j}$ $(i=1, \cdots x ; j=1, \cdots y) . \tau$ is distinguishing coefficient supposed to be 0.5 normally.

Subsequently, the grey relational grade, $\varepsilon_{i}$, is generated by $\sum_{j=1}^{y}$

$\sum_{j} \tau_{i j}, i=1,2 \cdots, x . \varepsilon_{j}$ is the weight of the $j^{\text {th }}$ criterion, where $\varepsilon_{j} \geq 0$ and $\sum_{j=1}^{y} \varepsilon_{j}=1$. Finally, ranking all of the criteria based on the value of the grey relational grade, the higher value $\varepsilon_{i}$ is, the more important criteria $A_{i}$ is (Deng, 1989).

\subsection{Converged IVTFNs -GRA}

In the fuzzy MCDM problem, let $A=\left\{A_{1}, A_{2}, \cdots, A_{x}\right\}$ and $S=$ $\left\{S_{1}, S_{2}, \cdots, S_{y}\right\}$ are finite sets of criteria and aspects. The weights

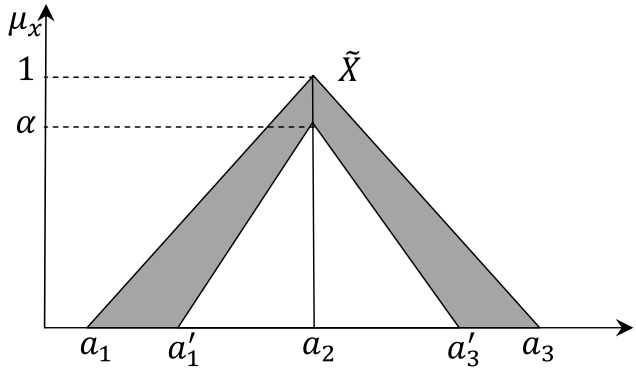

Fig. 1. An interval-valued triangular fuzzy number.

Table 1

Definitions of linguistic variables for the ratings.

\begin{tabular}{ll}
\hline Linguistic variables & Interval-valued TFNs \\
\hline Very poor $(\mathrm{VP})$ & {$[(0,0) ; 0 ;(0.1,0.15)]$} \\
Poor $(\mathrm{P})$ & {$[(0,0.05) ; 0.1 ;(0.25,0.35)]$} \\
Medium poor $(\mathrm{MP})$ & {$[(0,0.15) ; 0.3 ;(0.45,0.55)]$} \\
Medium $(\mathrm{M})$ & {$[(0.25,0.35) ; 0.5 ;(0.55,0.65)]$} \\
Medium good (MG) & {$[(0.45,0.55) ; 0.7 ;(0.8,0.95)]$} \\
Good $(\mathrm{G})$ & {$[(0.55,0.75) ; 0.9 ;(0.95,1)]$} \\
Very good $(\mathrm{VG})$ & {$[(0.85,0.95) ; 1 ;(1,1)]$} \\
\hline
\end{tabular}

of criteria $\varepsilon=\left(\varepsilon_{1}, \varepsilon_{2}, \cdots, \varepsilon_{n}\right)$ is unidentified, however it satisfies $\varepsilon_{j} \geq 0, j=1,2, \cdots x, \sum_{j=1}^{y} \varepsilon_{j}=1$.

Assume the criteria $A_{i}$ with relation to $S_{j}$ is defined as $\tilde{d}_{i j}$. The fuzzy decision matrix $\tilde{D}=\left[\tilde{d}_{i j}\right]_{x \times y}$. Where, $\tilde{d}_{i j}$ is described in IVTFNs as $\tilde{a}=\left\{\begin{array}{l}\left(a_{1}, a_{2}, a_{3}\right) \\ \left(a_{1}, a_{2}, a_{3}\right)\end{array}\right.$, it can be presented as $\tilde{a}=$ $\left[\left(a_{1}, a_{1}^{\prime}\right) ; a_{2} ;\left(a_{3}^{\prime}, a_{3}\right.\right.$ \$ee Fig. 1 .

This study proposed to integrate GRA with IVTFN, which presented as follows:

Compute the normalized decision matrix $\tilde{D}$ which can simply denote $\tilde{d}_{i j}=\left[\left(a_{i j}, a_{i j}^{\prime}\right) ; b_{i j} ;\left(c_{i j}^{\prime}, c_{i j}\right)\right]$ as shown in Table 1 . The normalized rating can be reformulated from Eqs (1) and (2), as shown below:

$$
\begin{aligned}
\tilde{d}_{i j} & =\left[\left(\frac{a_{i j}}{c_{j}^{\text {max }}}, \frac{a_{i j}^{\prime}}{c_{j}^{\text {max }}}\right) ; \frac{b_{i j}}{c_{j}^{\text {max }}} ;\left(\frac{c_{i j}}{c_{j}^{\text {max }}}, \frac{c_{i j}}{c_{j}^{\text {max }}}\right)\right], \\
i & =1,2, \cdots, x ; j=1,2, \cdots, y, \text { for } j \in B
\end{aligned}
$$

$$
\begin{aligned}
\tilde{d}_{i j} & =\left[\left(\frac{a_{j}^{\text {min }}}{c_{i j}}, \frac{a_{j}^{\text {min }}}{c_{i j}^{\prime}}\right) ; \frac{a_{j}^{\text {min }}}{b_{i j}} ;\left(\frac{a_{j}^{\text {min }}}{a_{i j}^{\prime}}, \frac{a_{j}^{\text {min }}}{a_{i j}}\right)\right], \\
i & =1,2, \cdots, x ; j=1,2, \cdots, y, \text { for } j \in C
\end{aligned}
$$

where $c_{j}^{\max }=\max _{i}\left\{c_{i j}, i=1 \cdots x\right\}$ and $a_{j}^{\min }=\min _{i}\left\{a_{i j}, i=1 \cdots x\right\}$. However, there are $t$ respondents in the decision group, the responses' feedback can be computed as below:

$$
\begin{aligned}
& \tilde{d}_{i j}=\frac{1}{t}\left(\tilde{d}_{i j}^{1}+\tilde{d}_{i j}^{2}+\tilde{d}_{i j}^{3}+\ldots . . \tilde{d}_{i j}^{t}\right)=\frac{1}{t} \sum_{1}^{t} \tilde{d}_{i j}^{t} \\
& i=1,2, \cdots, x ; j=1,2, \cdots, y ; t=1,2, \cdots, n
\end{aligned}
$$

The reference series can be acquired as follows:

$D_{0}=([(1,1) ; 1 ;(1,1)],[(1,1) ; 1 ;(1,1)], \ldots,[(1,1) ; 1 ;(1,1)])$ 
Table 2

GSCM aspects and criteria.

\begin{tabular}{|c|c|c|c|}
\hline Aspects & & Criteria & $\tilde{R}_{j}$ \\
\hline \multirow[t]{4}{*}{ AS1 } & \multirow[t]{4}{*}{ Process control } & C1 Reduce the use of fresh water and increase recyclability & 0.656 \\
\hline & & C2 Reduce dispersion of toxic and hazardous materials & 0.656 \\
\hline & & C3 Reduce greenhouse gas emissions & 0.656 \\
\hline & & C4 Reduce amount of hazardous waste generated & 0.656 \\
\hline \multirow[t]{7}{*}{ AS2 } & \multirow{7}{*}{ Environment } & C5 Environmental management system & 0.656 \\
\hline & & C6 Eco- innovation in R \& D & 0.536 \\
\hline & & C7 Green product and operation design & 0.558 \\
\hline & & C8 Waste reduction in operations process & 0.553 \\
\hline & & C9 Green purchasing control & 0.553 \\
\hline & & C10 Recycling the materials & 0.553 \\
\hline & & C11 Improvement in its compliance to environmental standards & 0.558 \\
\hline \multirow[t]{5}{*}{ AS3 } & \multirow{5}{*}{$\begin{array}{l}\text { Top management } \\
\text { support }\end{array}$} & C12 Achieve zero lost workdays as result of work-related injuries and illness & 0.553 \\
\hline & & C13 Increase the rate of employee suggested improvement in quality, social and environment health and safety performance & 0.553 \\
\hline & & C14 Increase employee training on green knowledge & 0.558 \\
\hline & & C15 Technological innovation as the main solution to un-sustainability & 0.558 \\
\hline & & C16 Design all green products can be disassembled, reused or recycled, free hazardous materials & 0.558 \\
\hline \multirow[t]{5}{*}{ AS4 } & \multirow[t]{5}{*}{ Supplier involvement } & C17 Improve corporate social responsibility & 0.548 \\
\hline & & C18 improvement in product green image & 0.553 \\
\hline & & C19 Percentage of suppliers participating in raw material or packaging life cycle assessment & 0.548 \\
\hline & & C20 Percentage of suppliers from the local area & 0.548 \\
\hline & & C21 Increase the durability of products & 0.553 \\
\hline \multirow[t]{3}{*}{ AS5 } & \multirow[t]{3}{*}{ Resilience } & C22 Reduce product defective rate or increase product yield rate & 0.558 \\
\hline & & C23 Reduce percent of products with take-back policies & 0.553 \\
\hline & & C24 Flexible and cleaner technology & 0.553 \\
\hline \multirow[t]{4}{*}{ AS6 } & \multirow[t]{4}{*}{ Long-term perspectives } & C25 Lifecycle management & 0.553 \\
\hline & & C26 Usage of effective systems and tools & 0.553 \\
\hline & & C27 Environmental activity capability & 0.558 \\
\hline & & C28 Reverse logistics & 0.553 \\
\hline \multirow[t]{6}{*}{ AS7 } & \multirow{6}{*}{$\begin{array}{l}\text { Operational } \\
\text { improvement }\end{array}$} & C29 Fine- Inventory management & 0.439 \\
\hline & & C30 Delivery performance in Eco-design & 0.558 \\
\hline & & C31 Cost reduction & 0.558 \\
\hline & & C32 Green Quality improvement & 0.548 \\
\hline & & C33 Efficiency in operations & 0.548 \\
\hline & & C34 Responsiveness to stakeholders & 0.548 \\
\hline
\end{tabular}

Note: Threshold value $=0.521$.

The distance, $\rho_{i j}$, between the reference value and each compar-ison value can be formulated, using Eq. (3)

$\rho_{i j}^{(B)}=\sqrt{\frac{1}{3}\left(a_{i j}^{\prime} / c_{j}^{\max }-1\right)^{2}+\left(b_{i j} / c_{j}^{\max }\right)+\left(c_{i j} / c_{j}^{\max }-1\right)^{2}}$

$\rho_{i j}^{\left(B^{\prime}\right)}=\sqrt{\frac{1}{3}\left(a_{i j} / c_{j}^{\max }-1\right)^{2}+\left(b_{i j} / c_{j}^{\max }\right)+\left(c_{i j}^{\prime} / c_{j}^{\max }-1\right)^{2}}$

$\rho_{i j}^{(C)}=\sqrt{\frac{1}{3}\left(a_{j}^{\min } / c_{i j}^{\prime}-1\right)^{2}+\left(a_{j}^{\min } / b_{i j}\right)+\left(a_{j}^{\min } / a_{i j}-1\right)^{2}}$

$\rho_{i j}^{\left(C^{\prime}\right)}=\sqrt{\frac{1}{3}\left(a_{j}^{\min } / c_{i j}-1\right)^{2}+\left(a_{j}^{\min } / b_{i j}\right)+\left(a_{j}^{\min } / a_{i j}^{\prime}-1\right)^{2}}$

The comparison value can be simplified as:

$\left\{\begin{array}{l}\rho_{i j}^{\prime}=\rho_{i j}^{(B)}-\rho_{i j}^{(C)} \\ \rho_{i j}^{\prime \prime}=\rho_{i j}^{\left(B^{\prime}\right)}-\rho_{i j}^{\left(C^{\prime}\right)}\end{array}\right.$

Where $\bar{\rho}_{i j}=\left[\rho_{i j}^{\prime}, \rho_{i j}^{\prime \prime}\right]$ defined as interval value and needs to convert it into crisp value due to the loss of information. The maximum $\left(\rho_{\text {max }}^{\prime}, \rho_{\text {max }}^{\prime \prime}\right)$ and minimum $\left(\rho_{\text {min }}^{\prime}, \rho_{\text {min }}^{\prime \prime}\right)$ presented as follows $\left\{\begin{array}{l}\rho_{\text {max }}^{\prime}=\max _{i j} \rho_{i j}^{\prime} \\ \rho_{\text {max }}^{\prime \prime}=\max _{i j} \rho_{i j}^{\prime \prime} \\ \rho_{\text {min }}^{\prime \prime}=\min _{i j} \rho_{i j}^{\prime \prime} \\ \rho_{\text {min }}^{\prime \prime}=\min _{i j} \rho_{i j}^{\prime \prime}\end{array}, i=1,2, \cdots, x ; j=1,2, \cdots, y(10)\right.$

To acquire the grey relational coefficient:

$\tau_{i j}^{\prime}=\left(\rho_{\text {min }}^{\prime}+\tau \rho_{\text {max }}^{\prime}\right) /\left(\rho_{i j}^{\prime}+\tau \rho_{\text {max }}^{\prime}\right)$,

$\tau_{i j}^{\prime \prime}=\left(\rho_{\text {min }}^{\prime \prime}+\tau \rho_{\text {max }}^{\prime \prime}\right) /\left(\rho_{i j}^{\prime \prime}+\tau \rho_{\text {max }}^{\prime \prime}\right), i=1,2, \cdots, x ; j=1,2, \cdots, y$
Where, $\tau$ has to be set 0.5 (Tseng, 2010).

To get $\varphi_{i}^{\prime}$ and $\varphi_{i}^{\prime \prime}$, to use weight $\varepsilon_{j}, j=1,2, \cdots, y$, to normalized the information as follows

$$
\varepsilon_{j}=\sum_{i=1}^{x}\left(\tau_{i j}^{\prime}+\tau_{i j}^{\prime \prime}\right) / \sum_{i=1}^{x} \sum_{j=1}^{y}\left(\tau_{i j}^{\prime}+\tau_{i j}^{\prime \prime}\right)(12)
$$

The interval value needs to assess with likelihood properties to convert into weights (Li et al., 2007).

(a) $0 \leq \mu(a \geq b) \leq 1$;

(b) $\mu(a \geq b)+\mu(b \geq a)=1$

(c) $\mu(a \geq b)+\mu(b \geq a)=0.5$ if $\mu(a \geq b)=\mu(b \geq a)$

(d) $\mu(a \geq b)=0$ ifa $a^{+} \leq b^{-}$

(e)For any interval numbers $a$, $\mathrm{b}$ and $c, \mu(a \geq c)=\mu(b \geq c)$ if $\mathrm{a} \geq \mathrm{b}$.

Once the $\varepsilon=\left(\varepsilon_{1}, \varepsilon_{2}, \cdots \varepsilon_{n}\right)$ is acquired, $\bar{\varphi}_{i}=\left[\varphi_{i}^{\prime}, \varphi_{i}^{\prime \prime}\right], i=$ $1,2, \cdots x$ used to present the interval value to evaluate the grey relational grade between the reference series and comparison series:

$$
\begin{aligned}
\varphi_{i}^{\prime} & =\sum_{j=1}^{n} \varepsilon_{j} \tau_{i j}^{\prime}, \\
\varphi_{i}^{\prime \prime} & =\sum_{j=1}^{n} \varepsilon_{j} \tau_{i j}^{\prime \prime}, i=1,2 \cdots, x
\end{aligned}
$$

The criteria, $A_{j}$, being not inferior to $A_{k}{ }^{\prime \prime}$ is denoted by $A_{j} \succcurlyeq A_{k}$. The likelihood of $A_{j} \succcurlyeq A_{k}$ is defined and measured by that $\bar{\varphi}_{j} \succcurlyeq \bar{\varphi}_{k}$, where $\bar{\varphi}_{j}$ and $\bar{\varphi}_{k}$ are corresponding grey relational grade interval numbers of criteria $A_{j}$ and $A_{k}$ in $A$, individually (Li et al., 2009). For shifting 
the interval value to use the concept of likelihood, the likelihood relation $A_{j} \succcurlyeq A_{k}$ for criteria $A_{j}$ and $A_{k}$ in $A$ can be defined as follows:

$\mu\left(A_{j} \succcurlyeq A_{k}\right)=\mu\left(\bar{\varphi}_{j} \succcurlyeq \bar{\varphi}_{k}\right)=\max \left\{1-\max \left\{\frac{\varphi_{k}^{\prime \prime}-\varphi_{j}^{\prime}}{L\left(\bar{\theta}_{j}\right)+L\left(\bar{\theta}_{k}\right)}, 0\right\}, 0\right\}$

Where $\bar{\theta}_{j}=\left[\varphi_{j}^{\prime}, \varphi_{j}^{\prime \prime}\right], \bar{\theta}_{k}=\left[\varphi_{k}^{\prime}, \varphi_{k}^{\prime \prime}\right], L\left(\bar{\theta}_{j}\right)=\varphi_{j}^{\prime \prime}-\varphi_{j}^{\prime}, L\left(\bar{\theta}_{k}\right)=\varphi_{k}^{\prime \prime}-$ $\varphi_{k}^{\prime}$

Hence, the likelihood relations can be assigned by the likelihood matrix

$$
\begin{aligned}
& \begin{array}{llll}
A_{1} & A_{2} & \ldots & A_{x}
\end{array}
\end{aligned}
$$

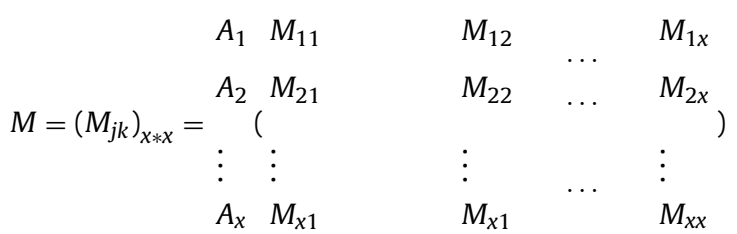

Convergence weight method

Matrix allows managing the interdependence within the measures. The interdependencies are presented among the aspects and criteria; the decision maker is required to offer the weight to adjust into column stochastic (Tseng et al., 2015). Then, it becomes a converged matrix $M^{*}$. Finally, the converged matrix $M^{*}$ can be acquired, which states the accurate relative weights within the measures.

$M=\lim _{* \rightarrow \infty} M^{*}$

Where, $M_{j k}=\mu\left(A_{j} \succcurlyeq A_{k}\right), j, k=1,2, \cdots, x$ for criteria $A_{j}$ and $A_{k}$ in A. Subsequently, the $M$ is a fuzzy judgment matrix. The ranking weights can be derived from the $v_{i}(i=1,2, \cdots, x)$ of $M$. The most weighted value $v_{i}$ yields the most important criteria $A_{i}(i=1,2, \cdots, x)$ (Zhang et al., 2011).

\subsection{Proposed analytical steps}

This study attempts to apply FDM to select the proper aspects and criteria and proposes IVTFN-GRA to assess the GSCM with 7 aspects and 34 criteria. The expert group followed the proposed analytical steps. The analytical steps are as follows:

1. The committee is to develop aspects and criteria and to compose survey instruments for evaluation and FDM employed to verify less weighted aspects. However, the aspects and criteria have the nature of complicated dependence relations. The traditional GRA decision matrix is developed, using Eqs. (1)-(3). The grey relational grade is acquired.

2. This study applied the IFTFN to normalize decision matrix into rating. The benefit and cost concerns can be acquired by following Eqs (4). and (5). Since expert committees need to integrate the various terms, using Eq. (6) to arrive at the average scores. The computation of cost and benefit distances need to contract with the reference values, using Eqs. (7) and (8). The distance values between benefit and cost matrices are acquired. Yet, the IFTFN-GRA, without cost and benefit involvement is followed by the important ranking on the GSCM aspect matrix.

3. Generate the grey relational coefficient and transfer it to the interval value. Once, the distance value is computed, it needs to be converted into the crisp value through Eq. (9). However, The GRA always assumes that the system information is incomplete, and applies Eqs. (10)-(12) to assist in generating the grey relational coefficient. Lastly, to transfer the grey relational coefficient into interval values using Eq. (13), the traditional GRA aspects coefficient is computed.

4. Computing the likelihood interaction matrix and analyzing the weights of aspects and criteria, apply Eq. (14). Following the likelihood to construct the likelihood matrix, use Eq. (15). The likelihood matrix can be generated by Eq. (16). The matrix decomposed with MATLAB 10 to acquire the Eigen-value for each of the criteria. The global weights of aspects are present. The comparison of traditional GRA, IVTFNs-GRA with/without cost and benefit concerns to the weighted average method is presented.

5. The converged weight method approach reality and the criteria with interdependence relations need to be computed, using Eq.(17).

\section{Results}

This section presents the study background and addresses how the GSCM is important to the case study and the analytical results presented in the sub-session. Hence, this session is focused on study background and analytical results.

\subsection{Study background}

A Taiwanese electronic manufacturing focal firm is to evaluate GSCM measurement which has been implemented using GSCM for past years. This firm is globally famous in producing mobile phones. Hence, this firm exports electronic products all over the world. This firm has been continuously developing eco-innovative, remarkably green products that consider social responsibility in their supply chain network. The evaluation aspects and criteria are extracted from their operational process. This firm is continuously enhancing its competitiveness and fully satisfies market and customer demands by developing a systematic GSC network. This study uses 7 aspects in the evaluation considerations, the management sought to conduct an evaluation of the supply chain network in green practices.

There are difficulties involved in this evaluation because the relevant costs and benefits are usually involved in all aspects. However, the initial stage of GSCM simply follows the green requirements from government regulations. The expert group included 10 professors and 10 industrial practitioners with intensive GSCM experiences. The 10 professors hold full professorship with more than 30 research papers published in the green supply chain field, while the 10 industrial practitioners have more than seven years working experience in related green practices. Hence, this study applied traditional GRA in their first stage of implementation. The second stage compared the IVTFN-GRA with and without cost and benefit concerns involved. Last, this study compared the weighted average method to test the appropriateness of proposed analytical tools. There are interdependence relations among the proposed measures. Hence, the un-converged matrix needs to take into the converged process. Table 2 presented the proposed evaluation measures. These evaluation measures, together with the 34 criteria, are collected through comprehensive literature review to enhance validity and reliability. It includes the aspects of process control, environment, top management support, supplier involvement, resilience, long-term perspective and operational improvement.

\subsection{Analytical results}

This study attempts to analyze how the proposed method compared to traditional GRA and IVTFN-GRA with and without cost and benefit concerns to address GSCM performance. The expert group followed the proposed analytical steps as follows:

1 An expert committee with intensive experiences in the industry developed the initial set of evaluation measures. The experts are to develop the measures and apply the FDM to verify and 
Table 3

Average values from respondents.

\begin{tabular}{|c|c|c|c|c|c|c|}
\hline AS1 & AS2 & AS3 & AS4 & AS5 & AS6 & AS7 \\
\hline$\left[\left(a_{1}, a_{1}^{\prime}\right) ; a_{2} ;\left(a_{3}^{\prime}, a_{3}\right)\right]$ & {$\left[\left(a_{1}, a_{1}^{\prime}\right) ; a_{2} ;\left(a_{3}^{\prime}, a_{3}\right)\right]$} & {$\left[\left(a_{1}, a_{1}^{\prime}\right) ; a_{2} ;\left(a_{3}^{\prime}, a_{3}\right)\right]$} & {$\left[\left(a_{1}, a_{1}^{\prime}\right) ; a_{2} ;\left(a_{3}^{\prime}, a_{3}\right)\right]$} & {$\left[\left(a_{1}, a_{1}^{\prime}\right) ; a_{2} ;\left(a_{3}^{\prime}, a_{3}\right)\right]$} & {$\left[\left(a_{1}, a_{1}^{\prime}\right) ; a_{2} ;\left(a_{3}^{\prime}, a_{3}\right)\right]$} & {$\left[\left(a_{1}, a_{1}^{\prime}\right) ; a_{2} ;\left(a_{3}^{\prime}, a_{3}\right)\right]$} \\
\hline
\end{tabular}

$\begin{array}{lllllllllllllllllllllllllllllllllllll}C & 0.164 & 0.164 & 0.3 & 0.479 & 0.364 & 0.279 & 0.693 & 0.529 & 0.371 & 0.65 & 0.507 & 0.393 & 0.386 & 0.6 & 0.629 & 0.407 & 0.371 & 0.529 & 0.579 & 0.686 & 0.179 & 0.35 & 0.714 & 0.543 & 0.707 & 0.379 & 0.421 & 0.529 & 0.579 & 0.586 & 0.193 & 0.55 & 0.586 & 0.671 & 0.679\end{array}$

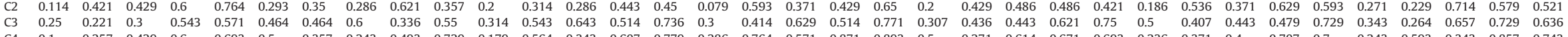

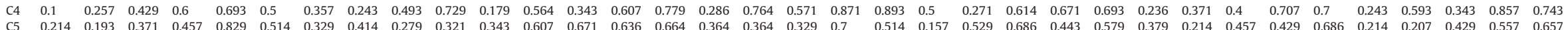

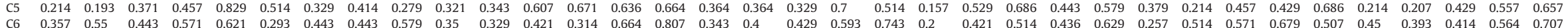

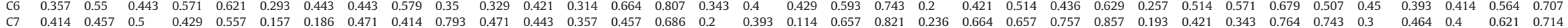

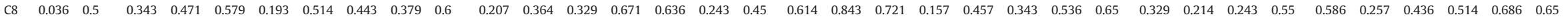

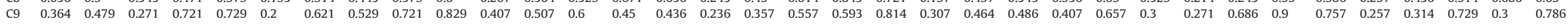

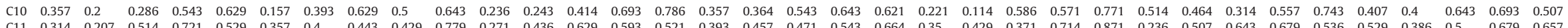

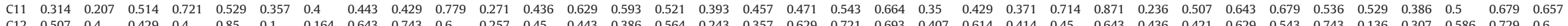

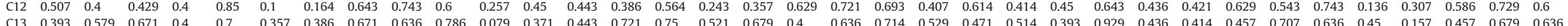

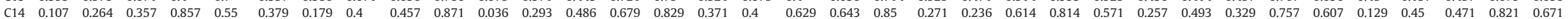

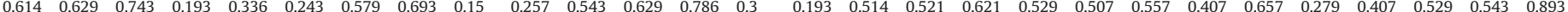

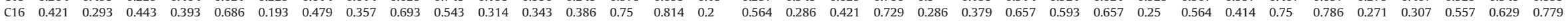

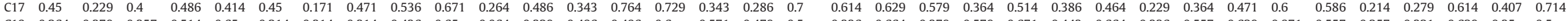

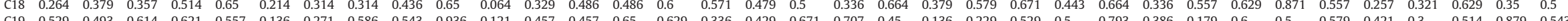

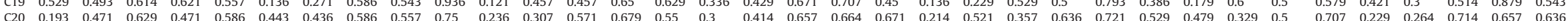

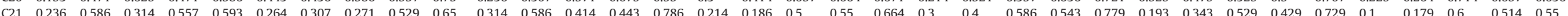

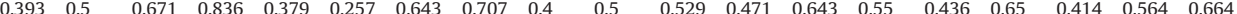
$\begin{array}{lllllllllllllllllllllllllllllllllllllll}\text { C23 } & 0.257 & 0.45 & 0.386 & 0.429 & 0.721 & 0.571 & 0.443 & 0.686 & 0.443 & 0.786 & 0.264 & 0.329 & 0.643 & 0.5 & 0.586 & 0.493 & 0.343 & 0.343 & 0.614 & 0.514 & 0.5 & 0.25 & 0.443 & 0.536 & 0.7 & 0.221 & 0.357 & 0.486 & 0.493 & 0.757 & 0.271 & 0.436 & 0.4 & 0.507 & 0.414\end{array}$

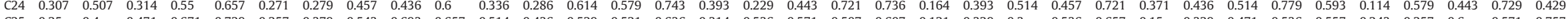

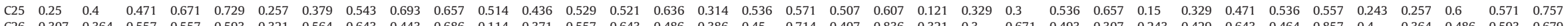

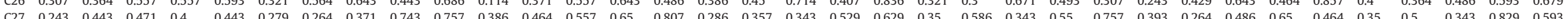

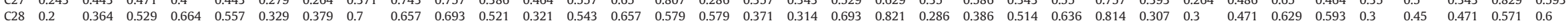

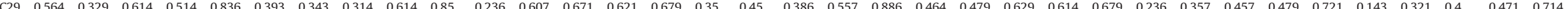

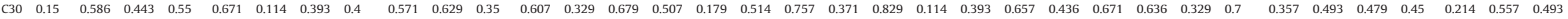

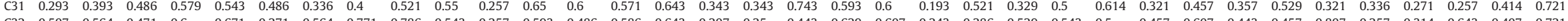

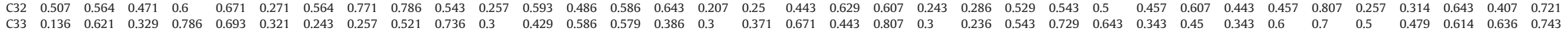

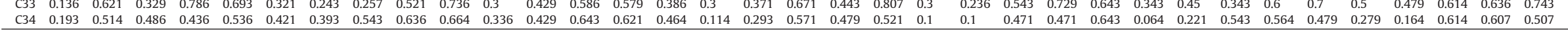


screen the most weighted GSCM attributes for further evaluation. Hence, the threshold value is computed as $\tilde{R_{j}}=0.521$. The validated aspects and criteria by FDM are proposed in Table 2. The traditional GRA applied Eqs. (1) and (3). The grey relational grades are AS1-0.236; AS2-0.208; AS3-0.096; AS4-0.039; AS50.195; AS6-0.125; and AS7-0.101.

2 This study presented the IVTFN-GRA to normalize a decision matrix into a rating presented in Table 3 . The benefit and cost concerns rating can be arrived through Eq. (4) and (6). The average scores of the expert group are acquired using Eq. (6). Then, the computation of distance needs to contrast with the refer-ence value by Eq. (7) and follows Eq. (8) to get the distance value among benefit and cost criteria. Table 4 is presented the benefit decision matrix. The cost decision matrix is presented in Table 5 .

However, if the computation step is without cost and benefit concerns in IVTFN, the computation is only based on the important rating on the GSCM aspect-criteria decision matrix. Therefore, the IVTFN decision matrix is similar to Table 5 . The IVTFNs- GRA aspects weights are acquired. The weights are AS1-0.218; AS2-0.163; AS30.085; AS4-0.081; AS5-0.172; AS6-0.103; and AS7-0.178.

3 Next, the proposed IVTFNs- GRA with cost and benefit concerns is applied. The cost and benefit decision matrices is to calculate the distance values, the distance values needed to convert into crisp value via Eq. (9). To overcome incomplete information, the system needs to apply Eqs. (10)-(12), which is the basic idea of GRA. Lastly. Table 6 presented the transference of the grey relational coefficients interval values, using Eq. (13).

4 Generate the likelihood matrix and analyzing the weighted aspects, using Eq. (14). Next, this step composes the likelihood matrix using Eq. (15). The likelihood matrix can be generated by Eq. (16). Afterward, the matrix is decomposed using MATLAB 10 to acquire the Eigen-value for each of the criteria. The Eigen values are AS1-0.137; AS2-0.134; AS3-0.144; AS4-0.311; AS5-0.454; AS6-0.662; AS7-0.449 and covert the Eigen values into weights (AS1-0.060; AS2-0.058; AS3-0.063; AS4-0.136; AS5-0.198; AS6-0.289; AS7-0.196). The higher the weighted Eigen-value presented the more GSCM important aspects. The result is presented in Table 7 .

Table 8 presented the comparisons of traditional GRA, IVTFNsGRA without cost and benefit, IVTFNs-GRA with cost and benefit and current average weighting method results. The results presented the proposed IVTFNs-GRA with cost and benefit concerns is closed to weighted average method weights. The real status aspect weights are AS1-0.096; AS2-0.085; AS3-0.130; AS4-0.098; AS5-0.257; AS6-0.175; AS7-0.159. Hence, this study would further analyzes the GSCM criteria.

5 Hence, the GSCM criteria needed to further compute the analytical solution. Table 9 presented the matrix of IVTFNs-GRA with cost and benefit criteria, Eigen-values and rankings. The criteria weights are C1-0.032; C2-0.015; C3-0.019; C4-0.039; C5-0.019; C6-0.046; C7-0.022; C8-0.032; C9-0.021; C10-0.020; C11-0.027; C12-0.028; C13-0.029; C14-0.032; C15-0.031; C16-0.027; C170.041; C18-0.032; C19-0.036; C20-0.013; C21-0.018; C22-0.043; C23-0.030; C24-0.033; C25-0.059; C26-0.016; C27-0.025; C280.029; C29-0.020; C30-0.027; C31-0.070; C32-0.025; C33-0.025; C34-0.0019. The ranking order is also presented.

The result from IVTFN-GRA with cost and benefit and weighted average method weights is quite similar. The top 3 aspects are 1 . Long-term perspectives; 2 . Resilience; and 3. Operational improvement. The top 5 criteria are 1 . Cost reduction; 2 . Lifecycle management; 3. Eco- innovation in R \& D; 4. Reduce product defective rate or increase product yield rate; and 5. Reduce amount of hazardous waste generated. Hence, the GSCM managerial implications are discussed.

\section{Managerial implications}

GSCM for a firm is implementing the design for environment and monitoring of all environmental activities with the objective of creating values, building a competitive infrastructure, leveraging reverse logistics, synchronizing supply with demand and measuring performances. The firms have to plan and improve their long-term perspectives and deal with the supply chain as a whole system to lower costs. GSCM requires a total environmental systems view and efficiency in the supply chain network that works efficiently, systematic planning, strategic integration of business functions and tactics across all operational functions. As a consequence of GSCM practices, costs must be lowered and environmental performance must be improved. The main focus is to turn to efficiency, environmental performance, added value for green products and customer satisfaction.

Eco-innovation in R \& D is the basic spirit to develop the products and processes that contribute to sustainable development. The commercial application of knowledge is to elicit direct or indirect ecological and economic improvements. This includes a range of ideas from technological advances to socially acceptable innovative paths. Additionally, the firm should be aware of how the technology innovation could continue to improve the value-added process that encompasses a continuum of the range of the related firms' activities in green technology and therefore to enhance the firms' competitive advantages. Especially, the focal firm is aware of ecoinnovation in their R \& D. The whole supply chain networks might follow and lean towards sustainability.

Operational improvement means to be made better in establishing a desired outcome in GSCM. For instance, focusing on the structure of an operation reveals how to contribute and maintain an effectiveness operational system. Yet, the operational process is also included in a strategic plan. The operational improvement in GSCM is to include a clear vision of what the firm wants to achieve. Improving and aligning an organization, that firm can find drastic environmental improvement to their business aspects. Especially, business functions are made up of a set of activities that need to eliminate waste, reduce variation, reduce product defective rate or increase product yield rate, reduce amount of hazardous waste generated and balance the workload to improve the overall operations. The firms are required to recognize clear comprehensive review of strengths, weaknesses, emergent opportunities and threats to your business in GSCM and employ them to find better solutions.

In addition, resilience is important to those who demonstrate a special pliability or adaptability when responding to uncertainty in GSCM. This resilient characteristic requires the firms to identify and compartmentalize the vision, goals, objectives, obstacles and the strategies when facing new and intimidating situations. The resilient organizations are used to mitigate unexpected disruptions by new green products and designs. However, in a supply chain networks, equipment and processes allows the manufacturing demand to be transfer to another manufacturing process within their network. GSCM includes multiple firms. As part of the environmental solution, life cycle assessment; design for environment; green raw materials requirements; visibility into their production schedules and capacities are essential for environmental controlling, transportation plan and controls are necessary. 
Table 4

IVTFNs -GRA with benefit decision matrix $(B)$.

\begin{tabular}{|c|c|c|c|c|c|c|}
\hline AS1 & AS2 & AS3 & AS4 & AS5 & AS6 & AS7 \\
\hline$\left[\left(a_{1}, a_{1}^{\prime}\right) ; a_{2} ;\left(a_{3}^{\prime}, a_{3}\right)\right]$ & {$\left[\left(a_{1}, a_{1}^{\prime}\right) ; a_{2} ;\left(a_{3}^{\prime}, a_{3}\right)\right]$} & {$\left[\left(a_{1}, a_{1}^{\prime}\right) ; a_{2} ;\left(a_{3}^{\prime}, a_{3}\right)\right]$} & $\left.\left(a_{1}, a_{1}^{\prime}\right) ; a_{2} ;\left(a_{3}^{\prime}, a_{3}\right)\right]$ & $\left.\left(a_{1}, a_{1}^{\prime}\right) ; a_{2} ;\left(a_{3}^{\prime}, a_{3}\right)\right]$ & {$\left[\left(a_{1}, a_{1}^{\prime}\right) ; a_{2} ;\left(a_{3}^{\prime}, a_{3}\right)\right]$} & $\left(a_{1}, a_{1}^{\prime}\right) ; a_{2} ;\left(a_{3}^{\prime}, a_{3}\right)$ \\
\hline
\end{tabular}

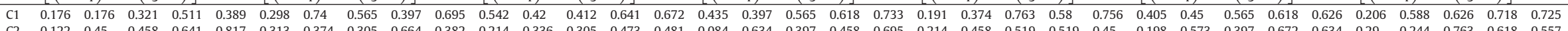

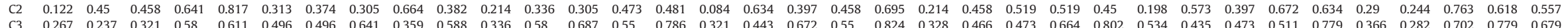

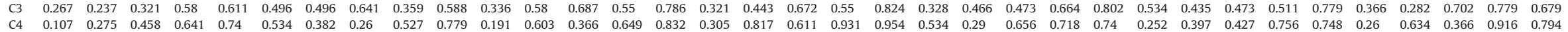

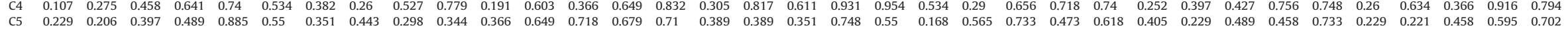

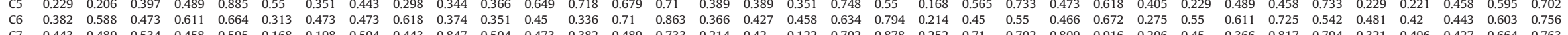

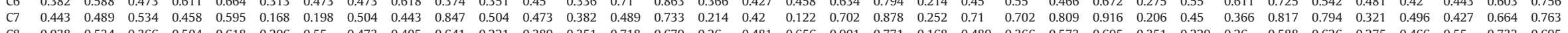

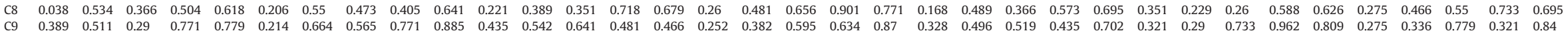

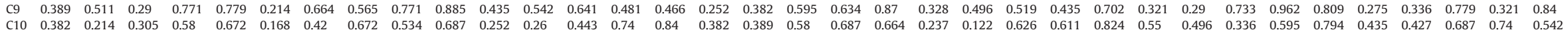

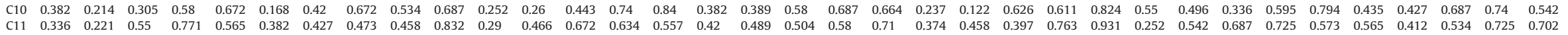

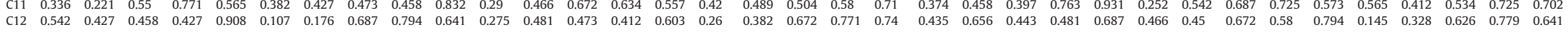

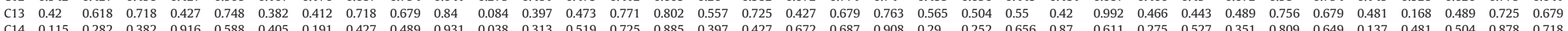

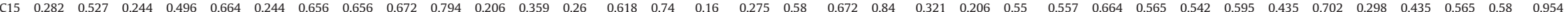

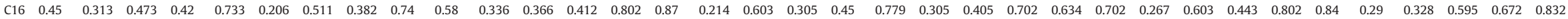

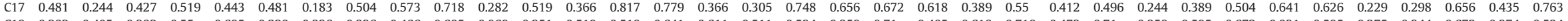

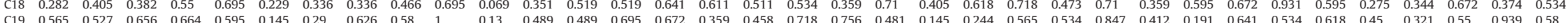

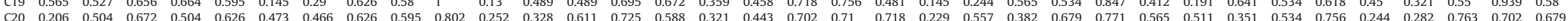

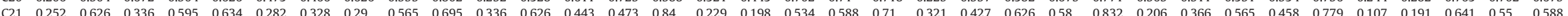
$\begin{array}{llllllllllllllll} & 0.5\end{array}$ $\begin{array}{lllllllllllllllllllllllllllllllllllllll}\mathrm{C} 23 & 0.275 & 0.481 & 0.412 & 0.458 & 0.771 & 0.611 & 0.473 & 0.733 & 0.473 & 0.84 & 0.282 & 0.351 & 0.687 & 0.534 & 0.626 & 0.527 & 0.366 & 0.366 & 0.656 & 0.55 & 0.534 & 0.267 & 0.473 & 0.573 & 0.748 & 0.237 & 0.382 & 0.519 & 0.527 & 0.809 & 0.29 & 0.466 & 0.427 & 0.542 & 0.443\end{array}$

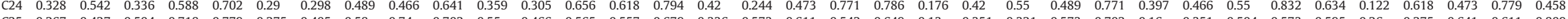

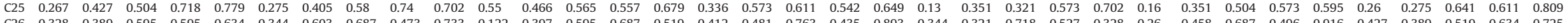

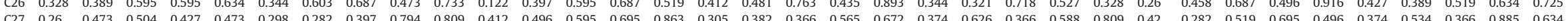

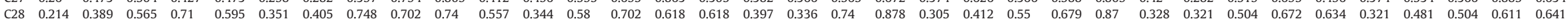

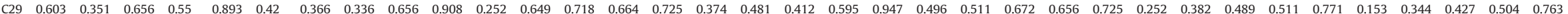
$\begin{array}{lllllllllllllllllllllllllllllllllllllllll}\text { C30 } & 0.16 & 0.626 & 0.473 & 0.588 & 0.718 & 0.122 & 0.42 & 0.427 & 0.611 & 0.672 & 0.374 & 0.649 & 0.351 & 0.725 & 0.542 & 0.191 & 0.55 & 0.809 & 0.397 & 0.885 & 0.122 & 0.42 & 0.702 & 0.466 & 0.718 & 0.679 & 0.351 & 0.748 & 0.382 & 0.527 & 0.511 & 0.481 & 0.229 & 0.595 & 0.527\end{array}$

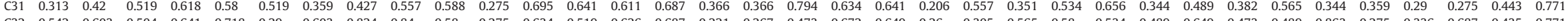

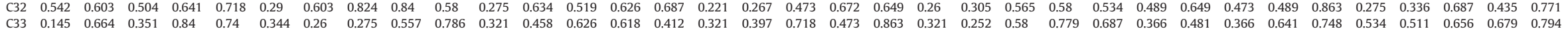

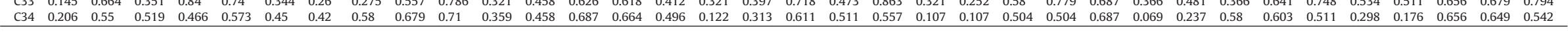


Table 5

IVTFNs -GRA with cost decision matrix (C).

\section{AS1}

$\left[\left(a_{1}, a_{1}^{\prime}\right) ; a_{2} ;\left(a_{3}^{\prime}, a_{3}\right)\right]$

$\left[\left(a_{1}, a_{1}^{\prime}\right) ; a_{2} ;\left(a_{3}^{\prime}, a_{3}\right)\right.$ AS3 $\left[\left(a_{1}, a_{1}^{\prime}\right) ; a_{2} ;\left(a_{3}^{\prime}, a_{3}\right)\right]$ AS4 $\left(a_{1}, a_{1}^{\prime}\right) ; a_{2} ;\left(a_{3}^{\prime}, a_{3}\right)$ AS5

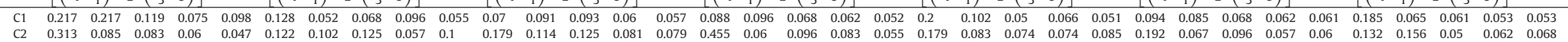

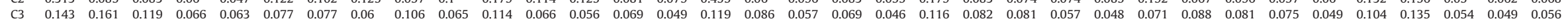

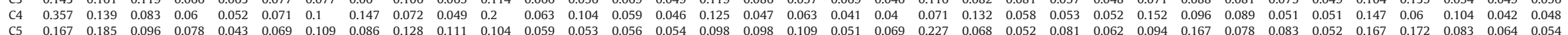

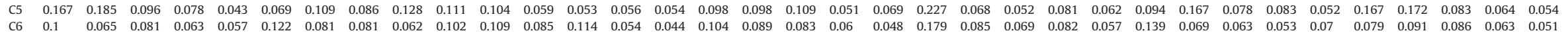

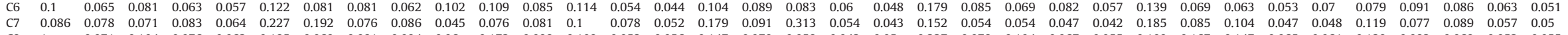

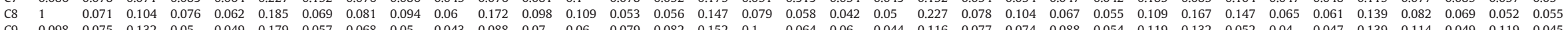
$\begin{array}{llllllllllllllllllllllllllllllllllll}\mathrm{C} 10 & 0.1 & 0.179 & 0.125 & 0.066 & 0.057 & 0.227 & 0.091 & 0.057 & 0.071 & 0.056 & 0.152 & 0.147 & 0.086 & 0.052 & 0.045 & 0.1 & 0.098 & 0.066 & 0.056 & 0.057 & 0.161 & 0.313 & 0.061 & 0.063 & 0.046 & 0.069 & 0.077 & 0.114 & 0.064 & 0.048 & 0.088 & 0.089 & 0.056 & 0.052 & 0.07\end{array}$

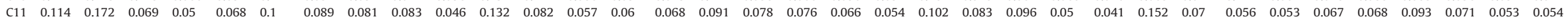

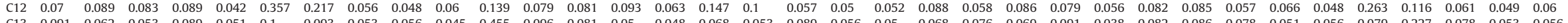

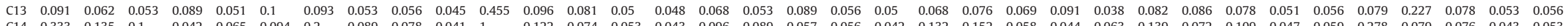

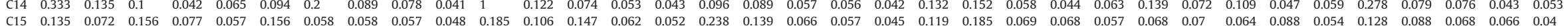

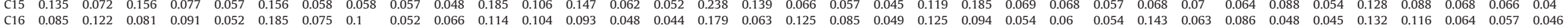

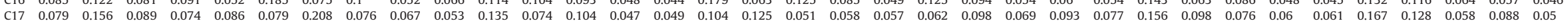

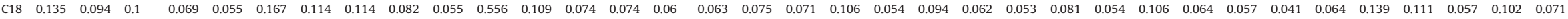

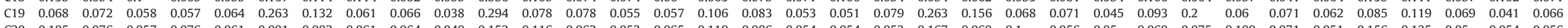

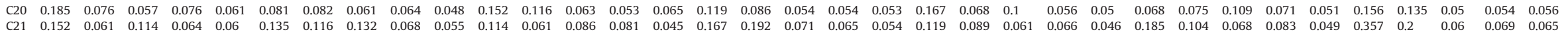

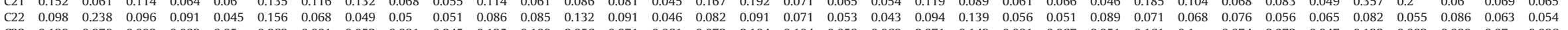

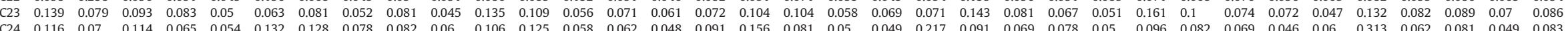

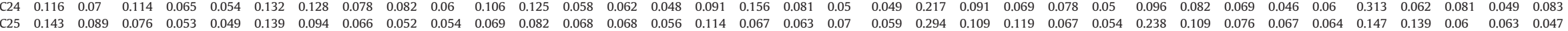

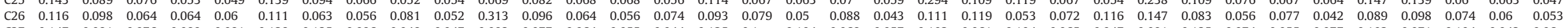

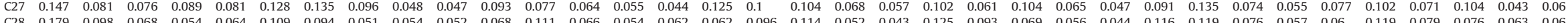

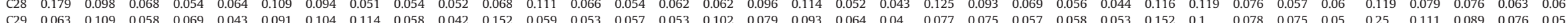

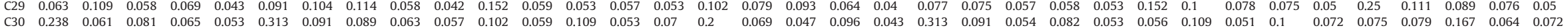

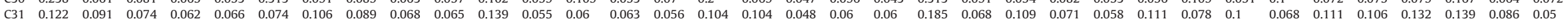
$\begin{array}{llllllllllllllllllllllllllllllllllll}\text { C32 } & 0.07 & 0.063 & 0.076 & 0.06 & 0.053 & 0.132 & 0.063 & 0.046 & 0.045 & 0.066 & 0.139 & 0.06 & 0.074 & 0.061 & 0.056 & 0.172 & 0.143 & 0.081 & 0.057 & 0.059 & 0.147 & 0.125 & 0.068 & 0.066 & 0.071 & 0.078 & 0.059 & 0.081 & 0.078 & 0.044 & 0.139 & 0.114 & 0.056 & 0.088 & 0.05\end{array}$

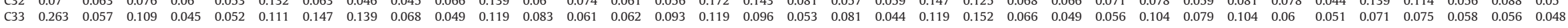

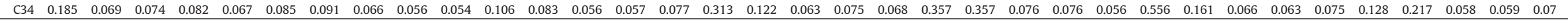


Table 6

IVTFNs-GRA with cost decision matrix- interval value of initial matrix.

\begin{tabular}{|c|c|c|c|c|c|c|c|c|c|c|c|c|c|c|}
\hline & AS1 & & AS2 & & AS3 & & AS4 & & AS5 & & AS6 & & AS7 & \\
\hline $\mathrm{C} 1$ & {$[0.155$} & $0.252]$ & {$[0.562$} & $0.055]$ & {$[0.413$} & $0.042]$ & {$[0.472$} & $0.044]$ & {$[0.486$} & 0.389] & {$[0.467$} & $0.450]$ & {$[0.544$} & $0.408]$ \\
\hline $\mathrm{C} 2$ & {$[0.398$,} & $0.105]$ & {$[0.252$} & $0.099]$ & {$[0.242$} & $0.175]$ & {$[0.363$} & $0.167]$ & {$[0.368$} & 0.319] & {$[0.410$} & $0.316]$ & {$[0.396$} & $0.425]$ \\
\hline $\mathrm{C} 3$ & {$[0.260$} & $0.142]$ & {$[0.490$} & $0.003]$ & {$[0.594$} & $0.030]$ & {$[0.532$} & $0.010]$ & {$[0.467$} & 0.400] & {$[0.461$} & $0.433]$ & {$[0.446$} & $0.495]$ \\
\hline C4 & {$[0.300$} & $0.146]$ & {$[0.332$} & $0.038]$ & {$[0.439$} & $0.082]$ & {$[0.675$} & $0.084]$ & {$[0.460$} & $0.549]$ & {$[0.402$,} & $0.360]$ & {$[0.464$} & $0.365]$ \\
\hline C5 & {$[0.308$} & $0.163]$ & {$[0.283$} & $0.106]$ & {$[0.620$} & $0.086]$ & {$[0.338$} & $0.022]$ & {$[0.515$} & $0.350]$ & {$[0.359$} & $0.352]$ & {$[0.322$} & $0.306]$ \\
\hline C6 & {$[0.487$} & $0.010]$ & {$[0.350$} & $0.052]$ & {$[0.404$} & $0.025]$ & {$[0.447$} & $0.003]$ & {$[0.439$} & $0.322]$ & {$[0.482$} & $0.432]$ & {$[0.438$} & $0.428]$ \\
\hline $\mathrm{C7}$ & {$[0.457$} & $0.008]$ & {$[0.322$} & $0.183]$ & {$[0.422$} & $0.014]$ & {$[0.213$} & $0.109]$ & {$[0.672$} & $0.472]$ & {$[0.391$,} & $0.325]$ & {$[0.451$} & $0.380]$ \\
\hline C8 & [0.239, & $0.193]$ & {$[0.431$} & $0.122]$ & {$[0.343$} & $0.087]$ & {$[0.536$} & $0.045]$ & {$[0.368$} & $0.269]$ & {$[0.240$} & $0.260]$ & {$[0.474$} & $0.415]$ \\
\hline C9 & {$[0.394$} & $0.011]$ & {$[0.579$} & $0.004]$ & {$[0.468$} & $0.016]$ & {$[0.476$} & $0.022]$ & {$[0.470$} & $0.354]$ & {$[0.479$} & $0.502]$ & {$[0.484$} & $0.343]$ \\
\hline $\mathrm{C} 10$ & {$[0.269$} & $0.110]$ & {$[0.460$} & $0.074]$ & {$[0.362$} & $0.067]$ & {$[0.457$} & $0.038]$ & {$[0.346$} & 0.329] & {$[0.422$} & $0.402]$ & {$[0.475$} & $0.527]$ \\
\hline C11 & {$[0.346$} & $0.026]$ & {$[0.453$} & $0.041]$ & {$[0.475$} & $0.007]$ & {$[0.478$} & $0.020]$ & {$[0.448$} & 0.407] & {$[0.510$} & $0.441]$ & {$[0.470$} & $0.527]$ \\
\hline C12 & {$[0.461$,} & $0.000]$ & {$[0.309$} & $0.130]$ & {$[0.412$} & $0.101]$ & {$[0.486$} & $0.019]$ & {$[0.497$,} & $0.386]$ & {$[0.544$} & $0.501]$ & [0.391, & $0.368]$ \\
\hline C13 & {$[0.612$} & $0.029]$ & {$[0.543$} & $0.078]$ & {$[0.350$} & $0.106]$ & {$[0.538$} & $0.087]$ & {$[0.537$,} & $0.446]$ & {$[0.456$} & 0.477] & {$[0.337$} & $0.433]$ \\
\hline $\mathrm{C} 14$ & {$[0.255$} & $0.135]$ & {$[0.339$} & $0.096]$ & {$[0.276$} & $0.137]$ & {$[0.546$} & $0.082]$ & [0.397, & 0.449] & {$[0.396$} & $0.348]$ & {$[0.428$} & $0.352]$ \\
\hline C15 & {$[0.328$} & $0.119]$ & {$[0.606$} & $0.017]$ & {$[0.285$} & $0.134]$ & {$[0.391$} & $0.085]$ & {$[0.353$} & $0.362]$ & {$[0.534$} & $0.464]$ & {$[0.501$} & $0.400]$ \\
\hline C16 & {$[0.392$,} & $0.053]$ & {$[0.374$} & $0.074]$ & {$[0.411$} & $0.005]$ & {$[0.392$,} & $0.134]$ & {$[0.500$} & $0.448]$ & {$[0.503$} & $0.391]$ & {$[0.453$} & $0.417]$ \\
\hline $\mathrm{C} 17$ & {$[0.284$} & $0.065]$ & {$[0.351$} & $0.036]$ & {$[0.429$} & $0.025]$ & {$[0.462$} & $0.044]$ & {$[0.400$} & $0.438]$ & {$[0.401$} & $0.360]$ & {$[0.425$} & $0.336]$ \\
\hline C18 & {$[0.373$} & $0.085]$ & {$[0.310$} & $0.150]$ & {$[0.289$} & $0.165]$ & {$[0.496$} & $0.014]$ & {$[0.603$} & $0.457]$ & {$[0.552$} & $0.521]$ & {$[0.400$} & $0.336]$ \\
\hline C19 & {$[0.528$,} & $0.140]$ & {$[0.412$} & $0.094]$ & {$[0.406$} & $0.087]$ & {$[0.467$} & $0.069]$ & {$[0.360$} & $0.296]$ & {$[0.369$} & $0.415]$ & {$[0.406$} & $0.504]$ \\
\hline $\mathrm{C} 20$ & {$[0.490$} & $0.059]$ & {$[0.538$} & $0.080]$ & {$[0.405$} & $0.023]$ & {$[0.525$} & $0.052]$ & {$[0.435$} & $0.328]$ & {$[0.428$} & 0.397] & {$[0.441$} & $0.432]$ \\
\hline $\mathrm{C} 21$ & {$[0.403$} & $0.082]$ & {$[0.298$} & $0.116]$ & {$[0.508$} & $0.044]$ & {$[0.339$} & $0.118]$ & {$[0.512$} & $0.426]$ & {$[0.428$} & $0.318]$ & {$[0.286$} & $0.281]$ \\
\hline $\mathrm{C} 22$ & [0.301, & $0.155]$ & {$[0.601$} & $0.048]$ & {$[0.370$} & $0.078]$ & [0.497, & $0.080]$ & {$[0.370$} & $0.493]$ & {$[0.483$} & $0.498]$ & {$[0.520$} & $0.434]$ \\
\hline $\mathrm{C} 23$ & {$[0.424$} & $0.093]$ & {$[0.582$} & $0.111]$ & {$[0.445$} & $0.032]$ & {$[0.343$} & $0.010]$ & {$[0.386$} & $0.434]$ & {$[0.433$} & $0.338]$ & {$[0.348$} & $0.325]$ \\
\hline $\mathrm{C} 24$ & {$[0.406$} & $0.056]$ & {$[0.360$} & $0.101]$ & {$[0.462$} & $0.019]$ & {$[0.381$} & $0.011]$ & {$[0.437$} & $0.313]$ & {$[0.474$} & $0.484]$ & {$[0.372$} & $0.320]$ \\
\hline $\mathrm{C} 25$ & {$[0.454$} & $0.017]$ & {$[0.461$} & $0.004]$ & {$[0.493$} & $0.074]$ & {$[0.528$} & $0.005]$ & {$[0.277$} & $0.223]$ & {$[0.350$} & $0.303]$ & {$[0.431$} & $0.394]$ \\
\hline $\mathrm{C} 26$ & {$[0.446$} & $0.006]$ & {$[0.588$} & $0.008]$ & {$[0.361$} & $0.090]$ & {$[0.588$} & $0.031]$ & {$[0.346$} & 0.409] & {$[0.543$} & $0.392]$ & {$[0.450$} & $0.445]$ \\
\hline $\mathrm{C} 27$ & {$[0.380$} & $0.106]$ & {$[0.358$} & $0.047]$ & {$[0.548$} & $0.078]$ & {$[0.356$} & $0.081]$ & {$[0.471$} & $0.363]$ & {$[0.350$} & $0.436]$ & {$[0.416$} & $0.403]$ \\
\hline C28 & {$[0.410$} & $0.043]$ & {$[0.527$} & $0.070]$ & {$[0.436$} & $0.103]$ & {$[0.402$} & $0.064]$ & {$[0.483$} & 0.419] & {$[0.388$} & 0.397] & {$[0.451$} & $0.393]$ \\
\hline $\mathrm{C} 29$ & {$[0.508$} & $0.107]$ & {$[0.380$} & $0.019]$ & {$[0.609$} & $0.027]$ & {$[0.460$} & $0.012]$ & {$[0.561$} & 0.539] & {$[0.417$} & $0.330]$ & {$[0.344$} & $0.261]$ \\
\hline C30 & {$[0.469$} & $0.085]$ & {$[0.345$} & $0.127]$ & {$[0.411$} & $0.009]$ & {$[0.598$} & $0.067]$ & {$[0.448$} & $0.316]$ & {$[0.445$} & $0.495]$ & [0.297, & $0.318]$ \\
\hline C31 & {$[0.417$} & $0.024]$ & {$[0.373$} & $0.002]$ & {$[0.587$,} & $0.012]$ & {$[0.493$} & $0.056]$ & {$[0.385$,} & $0.272]$ & {$[0.309$} & $0.326]$ & {$[0.289$} & $0.249]$ \\
\hline C32 & {$[0.530$} & $0.091]$ & {$[0.578$} & $0.083]$ & {$[0.516$} & $0.015]$ & {$[0.339$} & $0.091]$ & {$[0.363$} & $0.360]$ & {$[0.547$,} & $0.422]$ & {$[0.463$} & $0.367]$ \\
\hline C33 & {$[0.418$} & $0.080]$ & {$[0.283$} & $0.113]$ & {$[0.410$} & $0.008]$ & {$[0.524$} & $0.011]$ & {$[0.395$} & $0.432]$ & {$[0.416$} & $0.365]$ & {$[0.573$} & $0.558]$ \\
\hline C34 & {$[0.434$} & $0.099]$ & {$[0.485$} & $0.072]$ & {$[0.463$} & $0.044]$ & {$[0.335$} & $0.139]$ & {$[0.224$} & 0.193] & {$[0.229$} & $0.268]$ & {$[0.339$} & $0.393]$ \\
\hline
\end{tabular}

Table 7

The ranking result of aspects from IVTFNs-GRA with cost and benefit concerns.

\begin{tabular}{|c|c|c|c|c|c|c|c|c|c|c|}
\hline & AS1 & AS2 & AS3 & AS4 & AS5 & AS6 & AS7 & E-Value & Weights & Ranking \\
\hline AS1 & 0.500 & 0.514 & 0.469 & 0.498 & 0.000 & 0.000 & 0.000 & 0.137 & 0.060 & 6 \\
\hline AS2 & 0.486 & 0.500 & 0.464 & 0.489 & 0.000 & 0.000 & 0.000 & 0.134 & 0.058 & 7 \\
\hline AS3 & 0.531 & 0.536 & 0.500 & 0.520 & 0.000 & 0.000 & 0.000 & 0.144 & 0.063 & 5 \\
\hline AS4 & 0.502 & 0.511 & 0.408 & 0.500 & 1.000 & 0.000 & 0.000 & 0.311 & 0.136 & 4 \\
\hline AS5 & 1.000 & 1.000 & 1.000 & 0.000 & 0.500 & 0.491 & 0.498 & 0.454 & 0.198 & 2 \\
\hline AS6 & 1.000 & 1.000 & 1.000 & 1.000 & 0.509 & 0.500 & 1.000 & 0.662 & 0.289 & 1 \\
\hline AS7 & 1.000 & 1.000 & 1.000 & 1.000 & 0.502 & 0.000 & 0.500 & 0.449 & 0.196 & 3 \\
\hline
\end{tabular}

Table 8

The result of aspects comparisons with different approaches.

\begin{tabular}{|c|c|c|c|c|c|c|c|c|}
\hline \multirow[t]{2}{*}{ Methods } & \multicolumn{2}{|c|}{ Traditional GRA } & \multicolumn{2}{|c|}{ IVTFNs-GRA (without $C$ and $B$ ) } & \multicolumn{2}{|c|}{ IVTFNs-GRA (with C and B) } & \multicolumn{2}{|c|}{ Average weighting method } \\
\hline & Weights & Ranking & Weights & Ranking & Weights & Ranking & Weights & Ranking \\
\hline AS1 & 0.236 & 1 & 0.218 & 1 & 0.060 & 6 & 0.096 & 6 \\
\hline AS2 & 0.208 & 2 & 0.163 & 2 & 0.058 & 7 & 0.085 & 7 \\
\hline AS3 & 0.096 & 6 & 0.085 & 6 & 0.063 & 5 & 0.130 & 4 \\
\hline AS4 & 0.039 & 7 & 0.081 & 7 & 0.136 & 4 & 0.098 & 5 \\
\hline AS5 & 0.195 & 3 & 0.172 & 4 & 0.198 & 2 & 0.257 & 1 \\
\hline AS6 & 0.125 & 4 & 0.103 & 5 & 0.289 & 1 & 0.175 & 2 \\
\hline AS7 & 0.101 & 5 & 0.178 & 3 & 0.196 & 3 & 0.159 & 3 \\
\hline
\end{tabular}

\section{Conclusions}

This study concentrated on the comparison of traditional GRA, IVTFNs-GRA with and without cost and benefit concerns. The novelty is to present the converged weight method for IVTFNs-GRA with cost and benefit concerns to GSCM approach and present the converged weights and ranking for the aspects and criteria. The insightful and practical implications of the proposed work could be interpreted as follows. Firstly because many applications currently require fast processing on the MCDM, the IVTFNs-GRA with cost and benefit concerns could be used to simultaneously process those data without remarkably reducing the quality of outputted results. Secondly, the contribution is to expand a study direction about involved cost and benefit concerns as the picture converged IVTFNGRA. This study presents a novelty of converged weight method in IVTFN-GRA method to handle uncertainties, incomplete information and interdependence relations. The practitioners can be kept up-to-date with this proposed computation so that the proposed mechanism could be efficient for the GSCM. 
Table 9

Converged IVTFNs -GRA with cost and benefit concerns - the GSCM criteria ranking result.

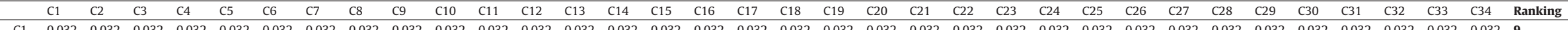

$\begin{array}{lllllllllllllllllllllllllllllllllllllllll}\mathrm{C} 1 & 0.032 & 0.032 & 0.032 & 0.032 & 0.032 & 0.032 & 0.032 & 0.032 & 0.032 & 0.032 & 0.032 & 0.032 & 0.032 & 0.032 & 0.032 & 0.032 & 0.032 & 0.032 & 0.032 & 0.032 & 0.032 & 0.032 & 0.032 & 0.032 & 0.032 & 0.032 & 0.032 & 0.032 & 0.032 & 0.032 & 0.032 & 0.032 & 0.032 & 0.032 & \mathbf{9} \\ \mathrm{C} 2 & 0.015 & 0.015 & 0.015 & 0.015 & 0.015 & 0.015 & 0.015 & 0.015 & 0.015 & 0.015 & 0.015 & 0.015 & 0.015 & 0.015 & 0.015 & 0.015 & 0.015 & 0.015 & 0.015 & 0.015 & 0.015 & 0.015 & 0.015 & 0.015 & 0.015 & 0.015 & 0.015 & 0.015 & 0.015 & 0.015 & 0.015 & 0.015 & 0.015 & 0.015 & 34\end{array}$

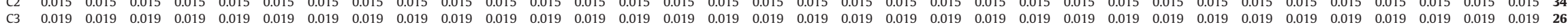

$\begin{array}{llllllllllllllllllllllllllllllllllll}\text { C4 } & 0.039 & 0.039 & 0.039 & 0.039 & 0.039 & 0.039 & 0.039 & 0.039 & 0.039 & 0.039 & 0.039 & 0.039 & 0.039 & 0.039 & 0.039 & 0.039 & 0.039 & 0.039 & 0.039 & 0.039 & 0.039 & 0.039 & 0.039 & 0.039 & 0.039 & 0.039 & 0.039 & 0.039 & 0.039 & 0.039 & 0.039 & 0.039 & 0.039 & 0.039 & \mathbf{5}\end{array}$

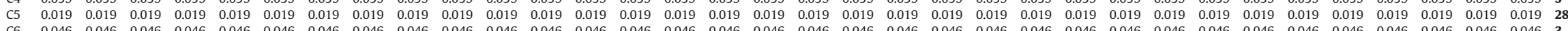

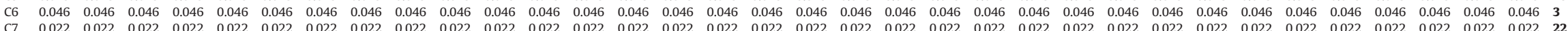

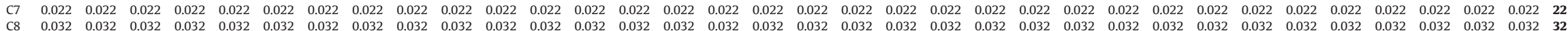

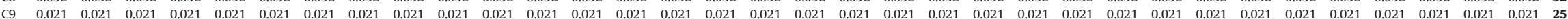

$\begin{array}{lllllllllllllllllllllllllllllllllllllllllllll}\mathrm{C} 10 & 0.020 & 0.020 & 0.020 & 0.020 & 0.020 & 0.020 & 0.020 & 0.020 & 0.020 & 0.020 & 0.020 & 0.020 & 0.020 & 0.020 & 0.020 & 0.020 & 0.020 & 0.020 & 0.020 & 0.020 & 0.020 & 0.020 & 0.020 & 0.020 & 0.020 & 0.020 & 0.020 & 0.020 & 0.020 & 0.020 & 0.020 & 0.020 & 0.020 & 0.020 & 23\end{array}$

$\begin{array}{llllllllllllllllllllllllllllllllllll}\mathrm{C} 11 & 0.027 & 0.027 & 0.027 & 0.027 & 0.027 & 0.027 & 0.027 & 0.027 & 0.027 & 0.027 & 0.027 & 0.027 & 0.027 & 0.027 & 0.027 & 0.027 & 0.027 & 0.027 & 0.027 & 0.027 & 0.027 & 0.027 & 0.027 & 0.027 & 0.027 & 0.027 & 0.027 & 0.027 & 0.027 & 0.027 & 0.027 & 0.027 & 0.027 & 0.027 & 20\end{array}$

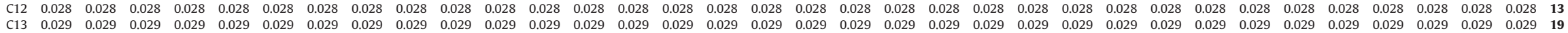

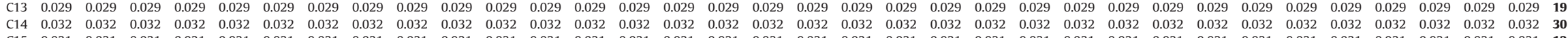

$\begin{array}{lllllllllllllllllllllllllllllllllllll}\text { C15 } & 0.031 & 0.031 & 0.031 & 0.031 & 0.031 & 0.031 & 0.031 & 0.031 & 0.031 & 0.031 & 0.031 & 0.031 & 0.031 & 0.031 & 0.031 & 0.031 & 0.031 & 0.031 & 0.031 & 0.031 & 0.031 & 0.031 & 0.031 & 0.031 & 0.031 & 0.031 & 0.031 & 0.031 & 0.031 & 0.031 & 0.031 & 0.031 & 0.031 & 0.031 & \mathbf{1 2}\end{array}$

$\begin{array}{llllllllllllllllllllllllllllllllllll}\mathrm{C} 17 & 0.041 & 0.041 & 0.041 & 0.041 & 0.041 & 0.041 & 0.041 & 0.041 & 0.041 & 0.041 & 0.041 & 0.041 & 0.041 & 0.041 & 0.041 & 0.041 & 0.041 & 0.041 & 0.041 & 0.041 & 0.041 & 0.041 & 0.041 & 0.041 & 0.041 & 0.041 & 0.041 & 0.041 & 0.041 & 0.041 & 0.041 & 0.041 & 0.041 & 0.041 & 7\end{array}$

$\begin{array}{lllllllllllllllllllllllllllllllllllllllllll}\mathrm{C} 18 & 0.032 & 0.032 & 0.032 & 0.032 & 0.032 & 0.032 & 0.032 & 0.032 & 0.032 & 0.032 & 0.032 & 0.032 & 0.032 & 0.032 & 0.032 & 0.032 & 0.032 & 0.032 & 0.032 & 0.032 & 0.032 & 0.032 & 0.032 & 0.032 & 0.032 & 0.032 & 0.032 & 0.032 & 0.032 & 0.032 & 0.032 & 0.032 & 0.032 & 0.032 & \mathbf{1 0}\end{array}$ $\begin{array}{llllllllllllllllllllllllllllllllllllllllll}\mathrm{C} 19 & 0.036 & 0.036 & 0.036 & 0.036 & 0.036 & 0.036 & 0.036 & 0.036 & 0.036 & 0.036 & 0.036 & 0.036 & 0.036 & 0.036 & 0.036 & 0.036 & 0.036 & 0.036 & 0.036 & 0.036 & 0.036 & 0.036 & 0.036 & 0.036 & 0.036 & 0.036 & 0.036 & 0.036 & 0.036 & 0.036 & 0.036 & 0.036 & 0.036 & 0.036 & \mathbf{6}\end{array}$

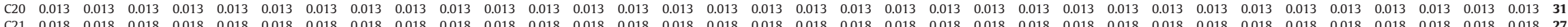

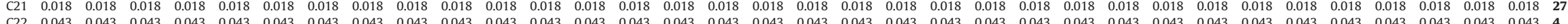

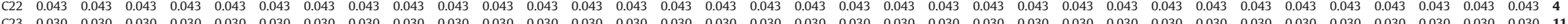

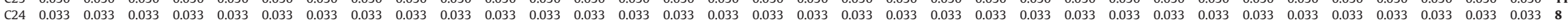
$\begin{array}{llllllllllllllllllllllllllllllllllll}\mathrm{C} 25 & 0.059 & 0.059 & 0.059 & 0.059 & 0.059 & 0.059 & 0.059 & 0.059 & 0.059 & 0.059 & 0.059 & 0.059 & 0.059 & 0.059 & 0.059 & 0.059 & 0.059 & 0.059 & 0.059 & 0.059 & 0.059 & 0.059 & 0.059 & 0.059 & 0.059 & 0.059 & 0.059 & 0.059 & 0.059 & 0.059 & 0.059 & 0.059 & 0.059 & 0.059 & 2\end{array}$

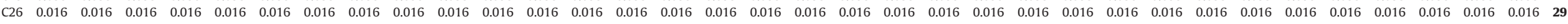
$\begin{array}{llllllllllllllllllllllllllllllllllllll}\mathrm{C} 27 & 0.025 & 0.025 & 0.025 & 0.025 & 0.025 & 0.025 & 0.025 & 0.025 & 0.025 & 0.025 & 0.025 & 0.025 & 0.025 & 0.025 & 0.025 & 0.025 & 0.025 & 0.025 & 0.025 & 0.025 & 0.025 & 0.025 & 0.025 & 0.025 & 0.025 & 0.025 & 0.025 & 0.025 & 0.025 & 0.025 & 0.025 & 0.025 & 0.025 & 0.025 & 18 & \end{array}$ $\begin{array}{lllllllllllllllllllllllllllllllllllllll}\mathrm{C} 28 & 0.029 & 0.029 & 0.029 & 0.029 & 0.029 & 0.029 & 0.029 & 0.029 & 0.029 & 0.029 & 0.029 & 0.029 & 0.029 & 0.029 & 0.029 & 0.029 & 0.029 & 0.029 & 0.029 & 0.029 & 0.029 & 0.029 & 0.029 & 0.029 & 0.029 & 0.029 & 0.029 & 0.029 & 0.029 & 0.029 & 0.029 & 0.029 & 0.029 & 0.029 & 16\end{array}$

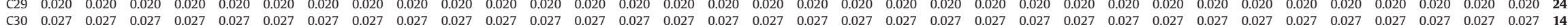

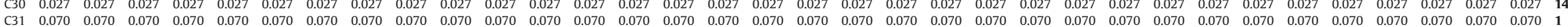
$\begin{array}{llllllllllllllllllllllllllllllllllll}\mathrm{C} 33 & 0.025 & 0.025 & 0.025 & 0.025 & 0.025 & 0.025 & 0.025 & 0.025 & 0.025 & 0.025 & 0.025 & 0.025 & 0.025 & 0.025 & 0.025 & 0.025 & 0.025 & 0.025 & 0.025 & 0.025 & 0.025 & 0.025 & 0.025 & 0.025 & 0.025 & 0.025 & 0.025 & 0.025 & 0.025 & 0.025 & 0.025 & 0.025 & 0.025 & 0.025 & 17\end{array}$

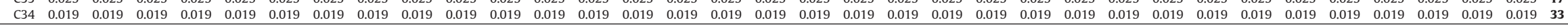


The results presented the decision making process with and without cost and benefit concerns in the GSCM of a firm's activities. This analysis highlighted the critical aspects and criteria that critically affect GSCM under uncertainties, while simultaneously considering 7 aspects and 34 criteria. Especially, those aspects and criteria are with interdependence relations in the firms' activities. These most weighted aspects and criteria are taken from the proposed hybrid method and verify the judgment results from the comparative analysis. Subsequently, an analytical recommendation solution for effective management includes the integration of cost and benefits concerns. If these aspects and criteria can be improved, the current GSCM could be enhanced. In addition, management should focus on improving the long-terms perspectives to address GSCM issue to further improve their performance. Understanding the GSCM can guide the focal firm to recommend operational criteria for future operations.

This study does not assume that a perfect, mathematical, hybrid MCDM method exists, interdependence of the peculiarities of the studied case is presented. For each type of decision, one or more equally suitable method may exist, which through understanding and appropriate use, can allow adjustments for alignment with the paradigms on which they are based, improve business performance, and permit consistent application with a well-evaluated method for focal firms in supply chain. This novel method can complement and refine the results by providing consecutive filters. Moreover, the future study might include more firms to develop a comparative study or extend the study time to compose a longitudinal study. From these insightful GSCM, further works of this theme could lay in several directions: (i) Extending cost and benefit in the context of proposed method; (ii) Adapting converged IVTFNGRA with cost and benefit concerns for other studies; (iii) applying this proposed method for some group decision making problems; and (iv) future research could utilize this hybrid method and these results to develop a detailed practical GSCM measures.

\section{Acknowledgements}

The authors would like to extend their sincere appreciation to the Ministry of Science and Technology of Taiwan for the financial support (103-2410-H-262-008), Liaoning Association for Science and Technology Project (LNKX2016C17) and the Dalian University of Technology Fundamental Research Fund(DUT16RC(3)038). Our deepest thanks also go to the referees for their constructive and fruitful comments.

\section{References}

Ashtiani, B., Haghighirad, F., Makui, A., Montazer, G.A., 2009. Extension of fuzzy TOPSIS method based on interval-valued fuzzy sets. Appl. Soft Comput. 9 457-461.

Cakir, O., Canbolat, M.S., 2008. A web-based decision support system for multi-criteria inventory classification using fuzzy AHP methodology. Expert Syst. Appl. 35, 1367-1378.

Chang, P.L., Hsu, C.W., Chang, P.C., 2011. Fuzzy Delphi method for evaluating hydrogen production technologies. Int. J. Hydrogen Energy 36, 14172-14179.

Deng, J., 1989. Introduction to grey system theory. J. Grey Syst. 1, 1-24. Ghorbani,

M., Arabzad, S.M., Shahin, A., 2013. A novel approach for supplier selection based on the Kano model and fuzzy MCDM. Int. J. Prod. Res. 51 (18), 5469-5484.

Hague, R.K., Barker, K., Ramirez-Marquez, J.E., 2015. Interval-valued availability framework for supplier selection based on component importance. Int. J. Prod. Res. 53 (20), 6083-6096.

Jabbour, A.B.L.S., Frascareli, F.C.O., Jabbour, C.J.C., 2015. Green supply chain management and firms' performance: understanding potential relationships and the role of green sourcing and some other green practices. Resour. Conserv. Recycl. 104, 366-374.

Kahraman, C., Beskese, A., Kaya, I., 2010. Selection among ERP outsourcing alternatives using a fuzzy multi-criteria decision making methodology. Int. J. Prod. Res. 48 (2), 547-566.
Kuo, Y.F., Chen, P.C., 2008. Constructing performance appraisal indicators for mobility of the service industries using Fuzzy Delphi Method. Expert Syst. Appl. 35, 1930-1939.

Li, G.D., Yamaguchi, D., Nagai, M., 2007. A grey based decision making approach to supplier selection problem. Math. Comput. Modell. 46, 573-581.

Lu, J., Wu, F., Zhang, G., 2007. On a generalized fuzzy goal optimization for solving fuzzy multi-objective linear programming problems. J. Intell. Fuzzy Syst. 18 (1), 83-97.

Luthra, S., Garg, D., Haleem, A., 2015. An analysis of interactions among critical success factors to implement green supply chain management towards sustainability: an Indian perspective. Resour. Policy 46, 37-50.

Malviya, R.K., Kant, R., 2016. Hybrid decision making approach to predict and measure the success possibility of green supply chain management implementation. J. Clean. Prod. 135, 387-409.

Murray, T.J., Pipino, L.L., Gigch, J., 1985. A pilot study of fuzzy set modification of Delphi. Hum. Syst. Manage. 5 (1), 76-80.

Olugu, E.U., Wong, K.Y., 2012. An expert fuzzy rule-based system for closed-loop supply chain performance assessment in the automotive industry. Expert Syst. Appl. 39, 375-384.

Rabbani, A., Zamani, M., Yazdani-Chamzini, A., Zavadskas, E.K., 2014. Proposing a new integrated model based on sustainability balanced scorecard (SBSC) and MCDM approaches by using linguistic variables for the performance evaluation of oil producing companies. Expert Syst. Appl. 41, 7316-7327.

Ren, J., Sovacool, B.K., 2014. Enhancing China's energy security: determining influential factors and effective strategic measures. Energy Convers. Manage. 88, 589-597.

Tadic, S., Ze`cević 1, S., Krstic, M., 2014. A novel hybrid MCDM model based onfuzzy DEMATEL, fuzzy ANP and fuzzy VIKOR for city logistics concept selection. Expert Syst. Appl. 41, 8112-8128.

Triantaphyllou, E., Lin, C.-T., 1996. Development and evaluation of five fuzzy multiattribute decision-making methods. Int. J. Approximate Reasoning 14 (4), 281-310.

Tsai, Y.Y., Lin, J.Y., Chen, M.S., Lin, M.-C., 2012. A grey decision and prediction model for investment in the core competitiveness of product development. Technol. Forecast. Soc. Change 78 (2011), 1254-1267.

Tseng, M.L., Chiu, A.S.F., 2013. Evaluating firm's green supply chain management in linguistic preferences. J. Clean. Prod. 40, 22-31.

Tseng, M.L., Lin, R.J., Lin, Y.H., Chen, R.H., Tan, K., 2014a. Close-loop or open hierarchical structures in green supply chain management under uncertainty. Expert Syst. Appl. 41 (7), 3250-3260.

Tseng, M.L., Lin, Y.H., Tan, K., Chen, R.H., Chen, Y.H., 2014b. Using TODIM to evaluate green supply chain management under uncertainty. Appl. Math. Modell. 38, 2983-2995.

Tseng, M.L., Lim, K.M., Wong, W.P., 2015. Sustainable supply chain management: a closed-loop network approach. Ind. Manage. Data Syst. 115 (3), 436-461.

Tseng, M.L., 2008. A causal and effect decision-making model of service quality expectation using grey-fuzzy DEMATEL approach. Expert Syst. Appl. 36 (4), 7738-7748.

Tseng, M.L., 2009. A causal and effect decision-making model of service quality expectation using grey-fuzzy DEMATEL approach. Expert Syst. Appl. 36 (4), 7738-7748

Tseng, M.L., 2010. Using linguistic preferences and grey relational analysis to evaluate the environmental knowledge management capacities. Expert Syst. Appl. 37 (1), 70-81.

Wang, T.C., Chang, T.H., 2007. Application of TOPSIS in evaluating initial training aircraft under a fuzzy environment. Expert Syst. Appl. 33 (4), 870-880.

Wang, R.T., Ho, C.T., Feng, C.M., Yang, Y.K., 2004. A comparative analysis of the operational performance of Taiwan's major airports. Air Transp. Manag. 10 (5), 353-360.

Wang Li, D.F., Liu, Y.C., Shan, F., 2009. Fractional programming methodology for multi-attribute group decision-making using IFS. Appl. Soft Comput. 9, 219-225.

Wang, Y.--., 2014. The evaluation of financial performance for Taiwan container shipping companies by fuzzy TOPSIS. Appl. Soft Comput. 22, 28-35.

Wu, K.J., Liao, C.J., Tseng, M.L., Chiu, A.S., 2015. Exploring decisive factors in green supply chain practices under uncertainty. Int. J. Prod. Econ. 159, 147-157.

Wu, K.J., Liao, C.J., Tseng, M., Chiu, K.K.S., 2016. Multi-attribute approach to sustainable supply chain management under uncertainty. Ind. Manage. Data Syst. 116 (4), 777-800.

Zhai, L.Y., Khoo, L.P., Zhong, Z.W., 2009. Design concept evaluation in product development using rough sets and grey relation analysis. Expert Syst. Appl. 36, 7072-7079.

Zhang, S.f., Liu, S.Y., 2011. A GRA-based intuitionistic fuzzy multi-criteria group decision making method for personnel selection. Expert Syst. Appl. 38, 11401-11405.

Zhang, S.f., Liu, S.Y., Zhai, R.h., 2011. An extended GRA method for MCDM with interval-valued triangular fuzzy assessments and unknown weights. Comput. Ind. Eng. 61, 1336-1341.

Zhu, Q., Sarkis, J., Lai, K.H., 2008. Confirmation of a measurement model for green supply chain management practices implementation. Int. J. Prod. Econ. $111(2)$ 261-273. 